\title{
A tese da primazia do reconhecimento sobre o conhecimento em Axel Honneth: contribuições para os processos educativos
}

\author{
Angelo Vitório Cenci \\ Universidade de Passo Fundo
}

Resumo: O artigo explora a tese honnethiana baseada no conceito de reconhecimento prévio da primazia do reconhecimento sobre o conhecimento. O objetivo é mostrar que tal tese, explicitada mediante os conceitos de reconhecimento prévio, gestos expressivos e atitude de implicação existencial, permite extrair importantes implicações educativas. Isso é indicado tanto no que tange à hipótese de uma continuidade entre os gestos expressivos de socialização infantil e as modalidades de aparição e de manifestação no espaço público mais amplo em que o sujeito agirá, quanto no que concerne às dimensões afetiva e cooperativa que estariam na base do reconhecimento humano e dos processos educativos.

Palavras-chave: Reconhecimento prévio. Conhecimento. Gestos expressivos. Implicação existencial. Processos educativos. 


\section{The thesis of the primacy of previous recognition over cognition: contributions to educational processes}

This paper explores the Honneth's thesis of the primacy of recognition over cognition, based on the concept of previous recognition. The aim is to show that Honneth's theses on the primacy of recognition over cognition, explained through the concepts of previous recognition, expressive gestures and attitude of existential implication, offers important educational implications. This is shown when related to the hypothesis of some continuity between the expressive gestures of children socialization and the modalities of appearing and manifestation in the broader public space in which the subject will act, and also with regard to the affective and cooperative dimensions that would be placed at the foundations of human recognition and educational processes.

Keywords: Previous recognition. Cognition. Expressive gestures. Existential implicature. Educational processes.

\section{La tesis de la primacía del reconocimiento sobre el conocimiento: contribuciones a los procesos educativos}

El artículo explora la tesis honnethiana de la primacía del reconocimiento sobre el conocimiento, basada en concepto de reconocimiento previo. El objetivo es mostrar que la tesis honnethiana de la primacía del reconocimiento acerca del conocimiento, explicada a través de los conceptos de reconocimiento anterior, gestos expresivos y actitud de implicación existencial, permite extraer importantes implicaciones educativas. Eso es indicado tanto en relación a la hipótesis de una continuidad entre los gestos expresivos de socialización infantil y las modalidades de aparición y de manifestación en el espacio público más grande en el que actuará el sujeto, cuanto en relación a las dimensiones afectiva y cooperativa que subyacen el reconocimiento humano y los procesos educativos.

Palabras-clave: Reconocimiento prévio. Conocimiento. Gestos expresivos. Implicación existencial. Procesos educativos 


\section{La thèse de La primauté de la reconnaissance sur la connaissancedans Alex Honneth: des contributions pour les processuséducatifs}

L'article recherche la thèsed'Honneth sur la primauté de la reconnaissance sur la connaissance, basée sur le concept de la reconnaissance précédente. Le but consistait à montrer que cette thèse, expliquée par les concepts de reconnaissance précédente, gestes ex pressifset attitude d'implication existentielle, permetd'extraire des importantes implications éducatifs. C'est indiqué quandil y a l'hypothèse de continuité entre les gestesexpressifs de socialisation des enfants et les modes de manifestation dansl'espacepubliqueoù le sujetagira et aussi concernant les dimensions affective et coopérative qui seraient au début de la reconnaissance humaine e des processusé du catifs.

Mots clés: Reconnaissance précédente. Connaissance. Gestesexpressifs. Implication existentielle. Processuséducatifs. 


\section{Introdução}

O presente estudo explora implicações educativas com base na tese de Honneth da primazia do reconhecimento sobre o conhecimento, sustentada no conceito de reconhecimento prévio. De modo mais específico, pretende-se explorar o potencial educativo decorrente do significado dos gestos expressivos e da atitude de implicação existencial que se origina a partir de tal tese ${ }^{1}$ Para tal, iniciaremos o percurso com uma breve apresentação sobre o modo como Honneth vai da formulação dos padrões de reconhecimento recíproco, em Luta por reconhecimento (1992), à proposição do conceito de reconhecimento prévio uma década depois sem, todavia, abandonar tais padrões (1). Na sequência, abordaremos a relação entre o reconhecimento prévio e o papel dos gestos expressivos e (2) a tese da primazia do reconhecimento prévio sobre o conhecimento (3) para, por fim, concluirmos, extraindo de tal tese, implicações para os processos educativos. Para dar conta de nossos propósitos, nos valeremos prioritariamente de dois textos do autor, a saber, Invisibilidade: sobre a epistemologia do reconhecimentoe Reificação: um estudo na teoria do reconhecimento. Nosso intuito é mostrar que a tese honnethiana da primazia do reconhecimento sobre o conhecimento, explicitada mediante os conceitos de reconhecimento prévio, gestos expressivos e atitude de implicação existencial, permite extrairimportantes implicaçõeseducativas, tanto no que tangeà hipótese de uma continuidade entre os gestos expressivos de socialização infantil e as modalidades de aparição e de manifestação no espaço público mais amplo em que o sujeito agirá,quanto no que concerne às dimensões afetiva e cooperativa que estariam na base o reconhecimento humano e dos processos educativos.

\section{Dos padrões de reconhecimento recíproco ao conceito de reconhecimento prévio}

A tese da precedência ou da primazia do reconhecimento sobre o conhecimento aparece na obra de Honneth mais de uma década depois da publicação de sua obra mais conhecida,Luta por reconhecimento, em 1992. É oportuno observar que com essa tese Honneth refere-se a um reconhecimento prévio, não a um conceito geral

1 Axel Honneth é sociólogo e filósofo filiado intelectualmente à tradição da teoria crítica da sociedade. O esforço principal de sua teoria crítica consiste em explicitar as expectativas morais de reconhecimento presentes nos processos de individualização, socialização, construção da identidade, integração social e reprodução cultural. Embora não se apresente como um autor que se ocupe diretamente de questões do campo educacional, nos últimos anos tem havido um crescente interesse na aproximação de sua obra com o campo da educação. Dentre outros estudos publicados no Brasil a esse respeito, vide Cenci (2011, 2013, 2013a, 2013b, 2015), Dalbosco (2011, 2014), Diaz (2011), Trevisan (2010), Fagundes; Trevisan (2014) e Dobon; Herzog; Martins (2017). 
de reconhecimento. Há, por conseguinte, a introdução de algo que não se fazia presente na abordagem inicial de sua teoria do reconhecimento. É oportuno retomar, pois, mesmo que sumariamente, a intenção principal do autor em seuLuta por reconhecimento. Nesse livro, Honneth opera com um conceito de reconhecimento recíproco que implica três padrões ou níveis de relações de reconhecimento, a saber: o amoroso, o jurídico e o social. $\mathrm{O}$ autor tem por objetivo dar à ideia hegeliana da luta por reconhecimento um caráter pós-metafísico, por meio de uma inflexão empírica via psicologia social de Mead. Honneth propõe-se a desenvolver um modelo de teoria social crítica baseada na luta por reconhecimento enquanto luta pela construção intersubjetiva da identidade pessoal e social.

Sua posição teórica é que o conflito é a base de toda interação humana e que a gramática deste é a luta por reconhecimento. A identidade pessoal, por conseguinte, é concebida como possuidora de uma estrutura intersubjetiva e essa tese, central de sua teoria social crítica, reporta ao nexo existente entre a experiência de reconhecimento e a relação do sujeito consigo próprio. Se, por um lado, esta autorrelação prática se amplia no envolvimento do sujeito com cada uma das formas de reconhecimento, possibilitando o desenvolvimento da autoconfiança, do autorrespeito e da autoestima, por outro, todavia, ela pode ser abalada quando afetada por experiências de desrespeito, privando a pessoa do reconhecimento de determinadas pretensões de sua identidade e, pois, ferindo a compreensão positiva que tem de si própria. O nexo entre experiência de reconhecimento e autorrelação prática indica que o indivíduo só pode se constituir como pessoa na medida em que, da perspectiva dos demais que o assentem ou encorajam, aprende a referir a si mesmo como alguém que possui determinadas capacidades e propriedades. Em resumo, em Luta por reconhecimento, Honneth desenvolve uma concepção de reconhecimento recíproco, sustentada em três padrões e guiada pelo esforço de atualizar a teoria da intersubjetividade de Hegel, traduzindo-a numa linguagem pós-metafísica, amparado, principalmente, em Mead.

Em obras da década seguinte, tais como Invisibilidade: sobre a epistemologia do reconhecimento (2003), Conhecer e reconhecer: sobre a teoria da intersubjetividade de Sartre (2003), Reconhecimento como ideologia (2004) e Reificação (2005), o autor vincula modificações e acréscimos importantes no que concerne ao núcleo original de sua teoria do reconhecimento. Além da formulação do conceito de reconhecimento prévio, aparece a discussão de temas referentes à deformação do reconhecimento na forma de, entre outros, invisibilidade social, ideologia e reificação. $\mathrm{O}$ aprofundamento feito nesse período sobre as deformações que afetam o reconhecimento recíproco é impulsionado pela interlocução com concepções filosóficas sobre o reconhecimento como as de Sartre, Margalit, Whitebook, Butler e Cavell, entre outras, e pelos resultados das pesquisas no campo da psicologia evolutiva, sobretudo as de Tomasello e Hobson, bem como os estudos de psicologia do desenvolvimento e da psicanálise de 
Daniel Stern (1980; 1992). Tal aprofundamento ajuda-o a avançar em novos aspectos acerca da complexa problemática da negação do reconhecimento e também em direção à formulação do conceito de reconhecimento prévio ${ }^{2}$.Percebe-se, ainda, nessa fase, que seu interesse pela psicologia social de Mead passa para um segundo plano e ocorre uma mudança na apropriação da teoria das relações objetais de Winnicott. ${ }^{3}$

Também é perceptível a abordagem das deformações do reconhecimento à luz de um diagnóstico de época mais elaborado ${ }^{4}$. Honneth passa a ocupar-se com as profundas transformações ocorridas no capitalismo contemporâneo neoliberal e suas consequências para os processos de individuação e de socialização humana. Essas preocupações teóricas são articuladas à dimensão ética de sua teoria do reconhecimento, inspirada em Hegel e orientada pela tarefa, própria a toda teoria crítica, de identificação das patologias sociais que afetam as condições de autorrealização dos sujeitos e, pois, a formação da própria identidade. Somado a esse aspecto, percebe-se sua aproximação às referências teóricas distintas daquelas que lhe possibilitaram elaborar originariamente sua concepção de reconhecimento recíproco no começo dos anos 90 do século passado.

Isso não quer dizer que tenha simplesmente abandonado o quadro teórico delineado em Luta por reconhecimento, mas sim operado transformações e acréscimos importantes em relação a ele. ${ }^{5}$ Indicativo da evolução ocorrida em sua teoria é a observação feita por ele mesmo de que o esquema de sua teoria do reconhecimento se centrara anteriormente nas categorias de reconhecimento e desrespeito. De qualquer modo, em seus trabalhos do início da primeira década deste século, aparecem modificações significativas em relação à moldura teórica de 1992 e o autor passa a tratar de uma forma de reconhecimento mais elementar que aquelas já expostas anteriormente sobre o tema. Como veremos na sequência, esse conceito é associado, entre outros

2 Em Luta por reconhecimento Honneth havia estabelecido, a partir de uma moldura hegeliana, a apresentação de uma estrutura das relações sociais de reconhecimento mediante uma correspondência entre formas de reconhecimento e formas de desrespeito. Vide, a esse respeito, Honneth (2003, p.211 - quadro). Vale observar não existir lá nenhuma forma de reconhecimento que se colocasse como prévia a essas três.

3 A esse respeito, vide Piromalli (2012).

4 Como o fornecido por Boltanski e Chiapello em O novo espírito do capitalismo (2009). O diagnóstico desses autores traça o perfil do novo espírito do capitalismo constatando que, a partir da metade dos anos 70 , o capitalismo começa a substituir o princípios fordistas da organização hierárquica do trabalho em prol da organização em rede centrada na iniciativa e na autonomia relativa do trabalho.

5 Por exemplo, em Redistribution or Recognition, de 2003, as esferas do reconhecimento -amor, direito e estima social- deixam de ser entendidas como dimensões ontológicas do desenvolvimento da personalidade, como o eram em 1992, e passam a ser abordadas como esferas (sociais) historicamente situadas (2003b, p. 138-150). Em seu livro de 2011, Das Recht der Freiheit, tais esferas converter-se-ão em expressão da liberdade. Antes disso, em seu livro sobre a Reificação, de 2005, do qual analisaremos aspectos no próximo item, postula uma dimensão existencial das esferas do reconhecimento (Honneth, 2007). 
aspectos, ao papel dos gestos corporais expressivos e a uma atitude de implicação existencial. ${ }^{6}$

\section{O reconhecimento prévio e o papel dos gestos expressivos}

Em seu ensaio Invisibilidade: sobre a epistemologia do reconhecimento (2006b), Honneth explora o significado dos gestos expressivos corporais associados à sua tese da primazia do reconhecimento sobre o conhecimento. Ali (2006b, p.230) distingue conhecimento de reconhecimento. De acordo com sua formulação o conhecimento é vinculado a um ato cognitivo não público, o de identificar alguém enquanto indivíduo, por suas características físicas, por exemplo. O reconhecimento, por sua vez, é um ato expressivo e implica a atribuição de um valor social à outra pessoa. O reconhecimento não se restringe ao conhecimento porque possui um conteúdo normativo que ultrapassa o âmbito cognitivo da identificação de um indivíduo. Se o reconhecimento depende de assegurar que a outra pessoa seja positivamente considerada como possuidora de valor social mediante um ato expressivo, a identificação do outro quando meramente cognitiva neutraliza a relação de reconhecimento mútuo aprendida pelos seres humanos desde tenra idade e que lhes é constitutiva. Nessa mesma linha de argumentação Honneth considera que o reconhecimento de uma pessoa somente pode efetivar-se com "o auxílio de meios que, em virtude de sua estrutura simbiótica, tem por modelo os gestos expressivos do corpo mediante os quais os seres humanos atribuem, uns aos outros, confirmação de seu valor social" (2006b, p.235).

O reconhecimento é tributário de gestos expressivos corporais em razão de que apenas tais gestos são capazes de traduzir publicamente a diferença entre conhecer e reconhecer. Esse tipo de reconhecimento positivo, oriundo do comportamento expressivo do parceiro de interação, permite ao sujeito saber-se reconhecido socialmente. Vale observar que essa posição amparada nos gestos expressivos corporais, baseada em Daniel Stern, coloca-se além daquela sustentada por Mead (1992). Este último postulara que o gesto se coloca no princípio originário de toda comunicação humana. Para um gesto se tornar significativo, convertendo-se inteligível para outros indivíduos, necessita ser internalizado. Mead distingue então gestos simples, onde não há antecipação do gesto do outro e nem reflexibilidade dos atos, de gestos significativos, que pressupõem reações refletidas, antecipação dos atos do outro e adequação da ação própria às condições sociais e ambientais. No âmbito social, os gestos assumem significado, convertendo-se em símbolos. $O$ gesto

6 Pode-se observar aqui influências de sua interlocução com as abordagens, entre outras, de Daniel Stern e Stanley Cavell. 
significativo converte-se então em linguagem e sua internalização possibilita tanto a constituição do self quanto a interação social e é, pois, o que permite ao sujeito adotar a atitude do outro. Para Mead, a linguagem é entendida como um dispositivo vinculado às expressões corporais humanas, como gestos, mãos e face.

Para Honneth, por seu turno, os significados expressivos dos gestos e da face, graças aos quais a criança é introduzida na interação social com o auxílio das pessoas de referência, é o que possibilita o aprender a atribuir um valor social ao outro. Esse parâmetro é buscado pelo autor nas pesquisas empíricas de Stern (1984; 1992), para quem a socialização da criança em seu primeiro ano toma a forma de um processo de regulação recíproca de afetos e de atenção mediante a comunicação gestual. Trata-se de gestos pré-linguísticos, como o sorriso e a empatia, com os quais a criança pequena aprende a aparecer socialmente ao interagir com gestos reativos. $\mathrm{O}$ reconhecimento manifesto nesse plano afetivo, numa perspectiva para além de Mead, precede tanto genética quanto estruturalmente a aquisição da linguagem (Cf. Honneth, 2006e, p.174). Para Honneth, as relações de reconhecimento entre adultos apresentam também essa forma expressiva. Ocorre que os gestos afirmativos e a expressões faciais espontâneas traduzem formas particulares de uma multiplicidade de expressões mediante as quais não apenas as crianças, mas mesmo os adultos podem exprimir informalmente, uns aos outros, simpatia ou atenção. Mesmo que variem consideravelmente em cada cultura, os gestos expressivos possuem uma função estruturante na comunicação interpessoal na medida em que possibilitam aos lactantes criar as condições para adotar a perspectiva das pessoas de referência e aos adultos entenderem as manifestações linguísticas de seus interlocutores.

Os gestos expressivos, por sua parte -linguísticos ou pré-linguísticos-, destinam-se a demonstrar de modo claro e público à pessoa em questão que lhe é concedida por alguém uma aprovação social ou que ela possui uma legitimidade social num papel específico. As formas positivas de expressão possuem uma importância fundamental na coordenação da ação social e Honneth considera ser possível ver nos gestos e respostas expressivas a forma mais elementar do reconhecimento social. Por essa razão, toda forma de reconhecimento social de uma pessoa depende de uma relação simbólica com gestos expressivos. Essas considerações levam-no a argumentar que o reconhecimento é tributário de gestos expressivos corporais em razão de que somente os sujeitos que "têm o sentimento de ser objeto desse conhecimento positivo, referido ao modo do comportamento expressivo de seu parceiro, se sabe reconhecido socialmente num nível elementar (Honneth, 2006b, p.235).

Para Honneth, os gestos expressivos de afirmação que manifestam o reconhecimento recíproco são performativos, portanto, ações. São ações que possuem nelas próprias o caráter de meta-ações por assinalarem simbolicamente um tipo de comportamento 
que pode ser esperadopelo parceiro de interação. A ideia de que os atos expressivos de reconhecimento representam meta-ações pode ser compreendida também por referência ao tipo de motivação indicada, como ocorre no caso do gesto afirmativo em que o sujeito manifesta uma motivação de segundo grau para agir de modo benevolente em relação a seu parceiro. Nessa perspectiva, a motivação ao engajamento de ações de reconhecimento pode ser considerada, na esteira de Kant, como algo resultante da apreciação do valor concedido aos seres humanos mediante suas propriedades inteligíveis ${ }^{7} . \mathrm{O}$ conceito kantiano de respeito (Achtung), retomado por Honneth por esse prisma, representa um descentramento do sujeito enquanto modo de limitação do seu ponto de vista egocêntrico. Trata-se de outorgar ao outro um valor incondicional, o que significa que o que intervém no reconhecimento do outro é, mediante as características percebidas no contexto de uma comunicação gestual entre adulto e criança, a manifestação expressiva de uma atribuição de valor equivalente às qualidades inteligíveis das pessoas. Nesse caso, a relação entre conhecer e reconhecer exprime que, se o reconhecimento não é expressão visível de uma identificação cognitiva, ele é, todavia, a expressão de uma percepção avaliativa.

Honneth entende que, ao final de tal processo, o adulto disporá -no quadro do vocabulário avaliativo de seu mundo social- de um leque de possibilidades que o tornará capaz de perceber o valor de uma pessoa. O estrato elementar desse valor será sempre a inteligibilidade do rosto humano e se tal valor assume a forma de uma percepção que inicia no sorriso endereçado ao bebê, a simples identificação cognitiva de uma pessoa perde a aparente prioridade sobre o reconhecimento. Essa compreensão do papel dos gestos expressivos humanos implica postular que, na interação social, as propriedades valorativas de uma pessoa são percebidas antes de qualquer outro aspecto. Tais gestos manifestam o valor positivo dos parceiros de interação, num processo de reconhecimento mútuo aprendido desde tenra idade através de gestos e expressões do olhar humano. Em decorrência, Honneth postula a hipótese da existência de uma continuidade entre os gestos expressivos de socialização infantil e as modalidades de aparição e de manifestação no espaço público mais amplo em que o sujeito agirá. ${ }^{8}$

\footnotetext{
7 Honneth observa, todavia, que os gestos expressivos podem se revestir de um caráter instrumental na medida em que, por exemplo, alguém simula ações de afeição benevolentes. Porém, esclarece que as reações negativas que essas falsificações provocam nas pessoas concernidas ou nos observadores exprimem "uma violação da gramática da comunicação gestual construída na segunda natureza de nosso mundo social” (2006b, p. 239-240, nota 9).
}

8 A esse respeito, vide Voirol (2005, p.24-5). 


\section{A tese da primazia do reconhecimento sobre o conhecimento e a atitude de implicação existencial}

Em seu livro sobre a reificação (2007) que, em certo sentido, pode ser lido como uma sequência da reflexão apresentada no texto sobre invisibilidade social, Honneth refere-se a um modo existencial que se encontra na origem de todas as demais formas de reconhecimento'. Trata-se de um reconhecimento prévio, tanto no sentido de anteceder os padrões de reconhecimento recíproco formulados anteriormente pelo autor -amor, direito e estima social-, quanto no de ter primazia sobre o conhecimento. Com base em tal conceito, a diferença entre reconhecimento e conhecimento reside no fato de que, enquanto a ação de reconhecer demanda gestos expressivos de cunho moral -como abordamos no item anterior-, o conhecer se limita a um ato de identificação cognitiva. Para Honneth, a precedência do reconhecimento sobre o conhecimento deve-se fundamentalmente ao fato de que a capacidade de identificação cognitiva de um ser humano pressupõe uma atitude prévia, aprendida, pois, desde a mais tenra idade, para perceber os parceiros de interação como pessoas possuidoras de valor. Trata-se da atitude de implicação existencial. O conceito de reconhecimento prévio compartilha, na linha do compromisso prático de Dewey, da cura heideggeriana e da implicação lukacsiana, a ideia da precedência de um "interesse existencial pelo mundo" nutrido pela experiência humana do caráter valioso deste (Honneth, 2007, p.55). A postura de reconhecimento assim concebida exprime a valoração do significado qualitativo que as demais pessoas ou coisas possuem para a nossa existência.

Para sustentar a tese de que a conduta de implicação vinculada ao reconhecimento prévio precede à apreensão neutra da realidade e, pois, o reconhecimento ao conhecimento, é necessário, a seu juízo, mostrar que subjacente a toda e qualquer relação humana objetivadora com o mundo está presente um estrato de implicação existencial. Nessa perspectiva, estaria na base da relação conosco, com os outros sujeitos e com o mundo um envolvimento emocional originário o qual representaria nossa práxis natural. Essa ideia é sustentada pela compreensão de que a especificidade da conduta humana se encontra na atitude de adoção de perspectiva. Essa posição permite a Honneth defender que tal atitude está enraizada numa interação prévia que possui, por sua vez, os traços de uma preocupação existencial.

A tese de que o reconhecimento precede o conhecimento é explicitada então por meio de duas dimensões. A primeira, ontogenética ou temporal, é formulada em discussão com a psicologia evolutiva (Tomasello e Hobson) e está baseada no

9 A esse respeito vide, por exemplo, Honneth (2007, p.81, nota 19). O autor refere também que essa distinção entre reconhecimento e conhecimento corresponderia ao primado do acordo comunicativo sobre o agir estratégico de Habermas, mas sem tomar como base para tal a distinção entre sistema e mundo da vida (Cf. 2006e, p.173). 
conceito de adoção de perspectiva (descentração); a segunda dimensão, a conceitual, é oriunda da discussão com a filosofia analítica (especialmente com Cavell, baseado em Witttgenstein), e se reporta ao conceito de implicação. Essa tarefa é levada adiante em dois passos. O primeiro é dado a partir de um ponto de vista genético, focando nas condições prévias da aquisição da capacidade de adotar uma perspectiva a ser desenvolvida pela criança. O reconhecimento prévio radica-se geneticamente em cada sujeito e estaria na origem de todas as outras formas de reconhecimento. No segundo passo, o autor vincula, de modo sistemático, provas para sua hipótese de que a capacidade de assumir racionalmente perspectiva se enraíza numa interação prévia que possui a feição de uma preocupação existencial.

Ao tratar da primeira de tais dimensões, Honneth observa que, para os aportes da psicologia evolutiva e para os estudos sobre a socialização, as capacidades de pensar e agir da criança surgem de um processo que se efetiva mediante a adoção de perspectiva ${ }^{10}$. Para essas abordagens, a criança aprenderia a vincular-se com o mundo dos objetos quando, da perspectiva de uma segunda pessoa, conseguiria atingir um descentramento progressivo de sua própria perspectiva, antes egocêntrica. Elas interpretam o fato de o bebê estabelecer, desde muito, cedo contato comunicativo com a pessoa de referência, a demandar seu olhar, etc., como a existência de uma fase de ensaio que possibilita à criança representar, pela primeira vez, os objetos de maneira objetiva, despersonalizada. Todavia, tais teorias, a exemplo de Mead e Devidson, ao tratarem da necessidade da adoção de perspectiva para o surgimento do pensamento simbólico, ignorariam o lado emocional da relação entre a criança e a pessoa de referência. A juízo de Honneth, elas incorreriam em "abstrações cognitivistas" que poderiam ser contornadas a partir do resultado das pesquisas com crianças autistas, como nas investigações de Hobson (Cf. Honneth, 2007, p.64). ${ }^{11}$

Afastando-se, nesse ponto, das abordagens propensas ao cognitivismo, e com base nas pesquisas de Hobson sobre o autismo, e nas de Tomasello sobre as origens culturais do conhecimento humano ${ }^{12}$, Honneth entende que, para esses dois autores, a criança somente pode levar adiante todos os passos da aprendizagem interativa se tiver desenvolvido antes um sentimento de união com a pessoa de referência. Se para Winnicott haveria nos primeiros meses de vida da criança muito mais uma simbiose com o ambiente do que uma ligação afetiva com a outra pessoa, para Stern

10 Honneth refere-se diretamente, nesse particular, a posturas teóricas que levam adiante uma síntese entre Piaget e Mead ou entre Davidson e Freud.

11 A teoria de Hobson se distingue das abordagens sobre o autismo -centradas na cognição- em razão de não atribuir a origem da conduta autista a carências cognitivas relacionadas a perturbações do pensamento ou da linguagem, mas à falta de capacidade de reação diante da presença emocional das pessoas de referência ou à falta de receptividade emotiva nos confrontos o mundo.

12 A partir dos estudos empíricos de Tomasello descobre-se que o desenvolvimento das habilidades de interação começam mais cedo do que a teoria de Mead imaginava. 
haveria na criança, nessa fase, já uma consciência elementar de si mesma e, pois, uma capacidade embrionária de se diferenciar em relação à pessoa de referência. O bebê experimentaria estados de simbiose com a mãe onde provaria sensações intensas de segurança mental e corporal, mas em situações episódicas determinadas, como no aleitamento, e não ainda como algo estável e permanente. Tais situações se caracterizariam como fusões afetivas mediante as quais a consciência incipiente do bebê seria temporariamente colocada em segundo plano perante a satisfação emotiva resultante de tal contato.13

Honneth argumenta então que o sentimento de união ou de identificação emocional do bebê com a pessoa que se constitui como sua referência primária é condição necessária para possibilitar à atitude adoção de perspectiva que leva ao desenvolvimento do pensamento simbólico (Cf. 2007, p.67). É somente em razão de uma disposição participativa que a criança pode estabelecer um vínculo afetivo com a pessoa de referência de modo que o reconhecimento primário concerne a uma disposição à participação emotiva. Trata-se de uma identificação emotiva com a pessoa amada, prévia à identificação cognitiva, e que permite assumir a perspectiva de uma segunda pessoa sobre o mundo. Nesse sentido, o colocar-se na perspectiva de uma segunda pessoa demanda uma forma de reconhecimento que não pode ser apreendida completamente mediante conceitos cognitivos ou epistêmicos. Isso se deve ao fato de tal forma de reconhecimento conter sempre um momento de abertura, entrega ou amor involuntário14 A juízo de Honneth, é essa implicação existencial, expressa na forma de dedicação emotiva, que permite à criança colocarse na perspectiva do outro de maneira a adquirir uma ideia ampliada e, pois, uma perspectiva despersonalizada da realidade que o rodeia.

O segundo sentido da tese da primazia do reconhecimento sobre o conhecimento é oriundo da discussão do autor com a filosofia analítica. Honneth se propõe a mostrar que as relações cognitivas do sujeito com o mundo vinculam-se ao reconhecimento também num sentido conceitual. Essa dimensão ontogenética de sua tese é assentada no fato de que a abundância de significados existenciais que os dados situacionais têm para os homens só pode ser compreendida pela criança quando tomada "a partir da perspectiva da pessoa amada" (Honneth, 2007, p.70). Por essa razão, nosso conhecimento é tanto mais adequado ou preciso quanto mais perspectivas conseguimos aprender sobre um objeto de percepção. Na criança pequena, essa adoção de perspectivas está ligada à condição não epistêmica de uma abertura emocional ou de identificação relacionada com as pessoas de referência. Em outros

13 A esse respeito também vide Piromalli (2012, p.310)

14 Essa consideração leva o autor a reportar-se a Adorno, na Minimamoralia, onde este afirma que um homem somente se torna homem imitando outros homens uma vez que a imitação configurar-se-ia como a forma primogênita de amor. 
termos, a criança deve tê-las primeiro reconhecido emocionalmente para poder desenvolver então um conhecimento da realidade objetiva. $O$ reconhecimento agrega, pois, um momento de implicação afetiva ou de identificação prévia, o que leva Honneth a concluir que o conceito positivo de implicação traduz um fato existencial que demanda a aprovação do valor do outro numa atitude de reconhecimento. Isso significa que os sujeitos percebem o outro sujeito diante de si com suas qualidades intelectuais em razão de serem afetados por estados de sensibilidade deste e isso ocorre de maneira a se sentirem motivados a reagir (Cf. Honneth, 2007, p.78).

Na perspectiva honnethiana, a tese comum tanto às teorias evolutivas da psicologia quanto à filosofia analítica de Cavell é a de que, na ação humana, existe uma primazia do reconhecimento sobre o conhecimento, ou seja, da implicação frente à apreensão neutra das demais pessoas. O reconhecer diz respeito não a uma atitude epistêmica, mas prática. Enquanto forma de reconhecimento prévio essa atitude prática é o que possibilita aos lactantes criar as condições necessárias para adotar a perspectiva de suas pessoas de referência. É essa mesma atitude que possibilitaria aos adultos entenderem as manifestações linguísticas de seus interlocutores.

\section{À guisa de conclusão: algumas implicações educativas da tese da primazia do reconhecimento sobre o conhecimento}

A introdução da tese da primazia do reconhecimento sobre o conhecimento representa o acréscimo de um elemento importante à teoria honnethiana e nos interessa extrair dela algumas implicações educativas. Com ela aparecem conceitos como reconhecimento prévio, gestos expressivos e atitude de implicação existencial que não se faziam presentes no espectro conceitual da formulação original de sua teoria. O reconhecer o outro é entendido como um processo mais originário do que o próprio autor postulara inicialmente.

(a) Uma primeira implicação da tese da primazia do reconhecimento sobre o conhecimento para a educação concerne ao papel desempenhado pelos gestos expressivos. $\mathrm{O}$ ato expressivo representado pelo reconhecimento do outro é o de atribuir um valor social à outra pessoa em razão de possuir um conteúdo normativo que ultrapassa sua identificação cognitiva. Como vimos, o papel dos gestos expressivos humanos permite postular que, na interação social, as propriedades valorativas de uma pessoa são percebidas antes de qualquer outro aspecto. Os gestos expressivos possibilitam um reconhecimento positivo do outro na medida em que permitem a ele saber-se reconhecido como tal. Esse assegurar-se do reconhecimento como pessoa 
de valor tem origem no significado expressivo dos gestos e da face manifesto desde tenra idade. $\mathrm{O}$ aprendizado efetivo de tais gestos é o que possibilita à criança ser introduzida na interação social com o auxílio das pessoas de referência e, portanto, podem ser entendidos como condição de possibilidade para aprender-se a perceber e para atribuir um valor social ao outro.

O reconhecimento manifesto nesse plano afetivo precede a aquisição da linguagem e é o que faz com que, depois, as relações de reconhecimento entre adultos venham a apresentar também essa forma expressiva. Como os gestos expressivos possuem uma função estruturante na comunicação interpessoal, possibilitam à criança as condições para aprender a adotar a perspectiva das pessoas de referência e aos adultos entenderem as manifestações linguísticas de seus interlocutores. Além de permitir aos seres humanos fornecerem uns aos outros a confirmação de seu valor social, as formas positivas de expressão gestual e da face possuem uma importância fundamental na coordenação da ação social. Eles são performativos, pois assinalam simbolicamente um tipo de comportamento esperado pelos parceiros de interação, podem ser entendidos como um elemento constitutivo de todos os processos de socialização humana e, desse modo, como basilares para o desenvolvimento dos processos educativos.

Honneth postula a hipótese da existência de uma continuidade entre os gestos expressivos de socialização infantil e as modalidades de aparição e de manifestação no espaço público mais amplo em que o sujeito agirá. Se essa continuidade pode ser postulada, como sugere o autor, e ela tem por base a confiança adquira via relações de reconhecimento intersubjetivo, é possível considerar então os processos educativos, tanto formais quanto informais, como imprescindíveis para sua garantia. A socialização infantil apresenta-se pelo prisma da primazia do reconhecimento sobre o conhecimento e, pois, da peculiaridade do papel dos gestos expressivos para o desenvolvimento dos sujeitos, como um esforço exigente e que deveria ser adequadamente atendido em tais processos. Do contrário, podem se constituir de forma deficitária e o envolvimento pessoal no espaço público ficar comprometido. Ter seu valor social confirmado pelo outro e saber o que pode ser esperado dos outros parceiros de interação pressupõe que a relação com o outro se sustente em uma forma positiva de expressão gestual e não na violência, por exemplo.

(b) Uma segunda implicação da tese honnethiana é extraída da atitude de implicação existencial. Como vimos, para Honneth a precedência do reconhecimento sobre o conhecimento deve-se fundamentalmente ao fato de a capacidade de identificação cognitiva de um ser humano pressupor uma atitude prévia -aprendida, pois, desde a mais tenra idade- para perceber-se e perceber os parceiros de interação como pessoas possuidoras de valor. Na base da relação conosco, com os outros sujeitos e 
com o mundo está um envolvimento emocional originário, atitude que, para Honneth, está enraizada numa interação prévia que possui, por sua vez, os traços de uma preocupação existencial.

Do diálogo com seus interlocutores, Honneth extrai que a criança somente pode levar adiante todos os passos da aprendizagem interativa se tiver desenvolvido antes um sentimento de união com a pessoa de referência. Por essa razão, entende, por exemplo, que o sentimento de união ou de identificação emocional do bebê com a pessoa que se constitui como sua referência primária é condição necessária para possibilitar a atitude adoção de perspectiva que leva ao desenvolvimento do pensamento simbólico e, portanto, da própria identidade. Essa ideia é sustentada pela compreensão de que a especificidade da conduta humana se encontra na atitude de adoção de perspectiva. É somente em razão de uma disposição participativa que a criança pode estabelecer um vínculo afetivo com a pessoa de referência de modo que o reconhecimento primário concerne a uma disposição a participação emotiva.

Trata-se de uma identificação emotiva com a pessoa amada, prévia à identificação cognitiva, e que permite, pois, assumir a perspectiva de uma segunda pessoa sobre $o$ mundo. Nesse particular, a formulação de Honneth traria uma importante contribuição aos processos educativos na medida em que ajudaria a dimensionar o papel dos afetos como central na estruturação e no êxito de tais processos. Se a identidade do sujeito somente se constitui por meio da adoção da perspectiva dos outros significativos atitude de implicação - os processos educativos deveriam primar tanto pela qualidade da identificação emotiva com as pessoas de referência quanto por criar as condições aos educandos para virem a adotar a perspectiva daquelas sobre o mundo.

Do ponto de vista educativo, a atitude de implicação existencial indica para a importância ou primazia do afeto e para a atenção à primeira infância. Num certo sentido isso pode ser lido como uma das condições fundamentais para o aprofundamento do significado do reconhecimento amoroso e das demais formas de reconhecimento intersubjetivo. Essa atitude estaria na base da capacidade do sujeito expressar-se como alguém que necessita ser considerado em suas necessidades, respeitado em sua dignidade e reconhecido em seu valor para a sociedade. Portanto, se antes na obra de Honneth o reconhecimento amoroso era base para o desenvolvimento dos demais padrões de reconhecimento, agora o reconhecimento prévio ou primordial assume esse papel. Não bastasse, esse conceito chama a atenção para a dimensão afetiva que estaria na base de todo o reconhecimento humano e, podemos acrescentar, dos próprios processos educativos.

(c) Entendendo as coisas desse modo tem-se que a propensão à cooperação seria originária no ser humano. Essa ideia aparece também na abordagem que Honneth 
faz sobre o reconhecimento como força motriz de grupos, ao destacar que "o eu busca o nós da vida comum em grupo, porque, mesmo depois de amadurecido, ele ainda depende de formas de reconhecimento social que possuam o denso caráter da motivação direta e da confirmação" (2013, p.77). Como na ação humana existe uma primazia do reconhecimento sobre o conhecimento, o reconhecer diz respeito a uma atitude prática ao invés de epistêmica. É tal atitude o que possibilita à criança em tenra idade aprender a adotar a perspectiva de suas pessoas de referência e também aos adultos entenderem as manifestações linguísticas de seus interlocutores. Tal atitude está na base dos processos de cooperação e, conforme mencionado acima, deve ter a marca da descentração que, em sentido ético-educativo, demanda a capacidade de assumir o ponto de vista moral, o colocar-se no lugar do outro.

Nesse sentido, ao invés de ser tomado como uma ameaça à identidade, o grupo, antes, deve ser concebido em sentido adorniano como uma "fonte da humanidade". Para Honneth (2013), a qualidade das interações no interior de grupos depende diretamente das condições de socialização que prevalecem nela. Pode-se postular que se tais condições forem orientadas por uma identificação positiva com pessoas de referência, consonante com o modelo (pedagógico) dos gestos expressivos e de implicação existencial, os processos educativos assumiriam um papel central na vida social e tenderiam a articular os processos de socialização infantil e a preparação para a atuação na esfera pública de modo mais satisfatório do que encontramos na atualidade.

\section{Referências}

ADORNO, T. W.MinimaMoralia.Paris: Editions Payot, 2001.

BOLTANSKI, L; CHIAPELLO, E. O novoespírito do capitalismo. São Paulo: Martins Fontes, 2009.

CENCI, A. V. Reconhecimento, realização de si e paideia: sobre o sentidoatual de umantigo ideal. In: BOMBASSARO, L. C.; DALBOSCO, C. A.; KUIAVA, E. A. (Orgs.) Pensarsensivel: homenagem a Jayme Paviani. Caxias do Sul: Educs, 2011. p. 317329. 
$\mathrm{CENCI}, \mathrm{A}$. V. Reconhecimento, conflito e formaçãonateoriacrítica de Axel Honneth. Educação e Filosofia, Uberlândia, v. 27, n. 53, p. 323-342, jun. 2013 a.

CENCI, A. V. Individualização e reconhecimento.Educação, Porto Alegre, v. 36, n. 03, p.314-324, dez. 2013b.

$\mathrm{CENCI}, \mathrm{A}$. V. Reconhecimento e progresso moral: aportes da concepção de modernidade deHonnethparaaideia de formaçãohumana. LinhasCríticas, Brasília, v. 19 , n. 39, p. 271-288, maio/ago. 2013c.

CENCI, A. V.Autonomia, reconhecimento e educação. PráxisEducativa, Ponta Grossa, v. 10, n. 1, p. 253-274, jan./jun. 2015. Disponívelem: http://www.revistas2. uepg.br/index.php/praxiseducativa.

DALBOSCO, C. A. Reificação, reconhecimento e educação. RevistaBrasileira de Educação, Rio de Janeiro, v. 16, n. 46, p. 33-51, jan./abr. 2011. DOI: 10.1590/ S1413-24782011000100003

DALBOSCO, C. A. Condiçãohumana e formaçãovirtuosa da vontade: profundezas doreconhecimentoemHonneth e Rousseau. Educação e Pesquisa, São Paulo, v. 40, n. 3, p.799-812, jul./set. 2014. DOI: 10.1590/s1517-97022014091625

DIAZ, A. Educación, reconocimiento y ciudadanía. REP - RevistaEspaçoPedagógico, v. 18, n. 2, Passo Fundo, p. 259-270, jul./dez. 2011.

HERNÁNDEZ I DOBON, F. J; HERZOG, B; MARTINS, M. R.La educación y la teoríadelreconocimiento: entrevista aAxel Honneth. Educação\&Realidade, Porto Alegre, v. 42, n. 1, p. 395-406, ene./mar. 2017.http://dx.doi.org/10.1590/2175623670297.

FAGUNDES, A.; TREVISAN, A. L. A reificação da formaçãodocente e aonipresença dascompetências. Espaçopedagógico, Passo Fundo, v. 21, n. 1, p. 110-131, jan./ jun. 2014.DOI: /10.5335/rep.v21i1.3876.

HONNETH, A. Grounding Recognition: A Rejoinder to Critical Questions, in Inquiry: An Interdisciplinary Journal of Philosophy, v.XLV, n. 4, p. 499-519, 2002.

HONNETH, A. Luta por reconhecimento: a gramática moral dos conflitos sociais. São Paulo: Editora 34, 2003.

HONNETH, A. Redistribution as recognition: a response to Nancy Fraser. In: FRASER, N; HONNETH, A. Redistribution or Recognition. London/New York: Verso, 2003b. p. 110-197.

HONNETH, A.The point of recognition: a rejoinder to the rejoinder. In: FRASER, 
N; HONNETH, A. Redistribution or Recognition. London/New York: Verso, 2003c. p. 237-267.

HONNETH, A. Erkennen und Anerkennen: ZuSartresTheorie der Intersubjektivitat. In: Unsichtbarkeit:StationeneinerTheorie der Intersubjektivität. Frankfurt a.M.: Suhrkamp, 2003.

HONNETH, A. La societédumépris.Paris: La découverte, 2006.

HONNETH, A. La reconnaissancecommeidéologie. In: La societédumépris.Paris: La Découverte, 2006a, p.245-274.

HONNETH, A. Invisibilité: surl épistémologie de lareconnaissance. In: La societé du mépris.Paris: La Découverte, 2006b, 225-243.

HONNETH, A.; HARTMANN, M. Les paradoxes du capitalisme: unprogramme de recherche. In: La societé du mépris.Paris: La découverte, 2006c, p.275-303.

HONNETH, A. Capitalismeetréalisation de soi: les paradoxes de l'individuation In:La societé du mépris.Paris: La découverte, 2006d, p.305-323.

HONNETH, A.; VOIROL, O. La théorie critique de l'ecole de Francfortet la théorie de la reconnaissance. In: La societé du mépris.Paris: La découverte, 2006e, p.151180.

HONNETH, A. Reificación: um estudioenla teoria delreconocimiento. Buenos Aires: Katz, 2007.

HONNETH, A. Rejoinder. In: PETHERBRIDGE, D. (Ed.) Axel Honneth: Critical Essays.Leiden/Boston: Brill, 2011, p.391-421.

KANT, I. Critique de laraison pratique. Paris:ÉditionGallimard, 1985.

MEAD, G. H. Mind, self and society: from the standpoint of a social behaviorist. Chicago: The University of Chicago Press, 1992.

PIROMALLI, E. La teoria delriconoscimentodiAxel Honneth: dalle sue origini a Das Recht der Freiheit. Roma. UniversitáSapienza, 2012 (Tese de doutorado).

STERN, D.La primerarelación madre-hijo. Madrid: Morata, 1984.

STERN, D. O mundo interpessoal do bebê: uma visão a partir da psicanálise e da psicologia do desenvolvimento.Porto Alegre: Artes Médicas 1992

TOMASELLO, M. Origens culturais da aquisição do conhecimento humano. São Paulo: Martins Fontes, 2003. 
TOMASELLO, M. Por quécoperamos? Madrid: Katz, 2010.

TREVISAN, A. L.; ROSSATTO, N. D. Reificação e reconhecimento: reflexões para apesquisa em educação. Linhas Críticas, Brasília, v. 16, n. 31, p. 275-286, jul./dez. 2010.

VOIROL, O. Présentation - Visibilité et invisibilité: une introduction.Réseaux, n. 129130, p.9-36, 2005/1.

Recebido em fevereiro de 2016

Aprovado em março de 2017

Angelo Vitorio Censi é Professor do curso de filosofia e do programa de pós-graduação em educação da Universidade de Passo Fundo/RS. Email: angelovcenci@gmail.com 